\title{
Gastric diverticulum
}

\section{Pazhanivel Mohan MD, Murali Ananthavadivelu MD, Jayanthi Venkataraman MD}

Previously published at www.cmaj.ca

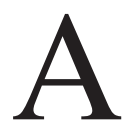

58-year-old man presented with a one-month history of upper abdominal pain and anorexia. There was no history of dysphagia, vomiting, hematemesis, melena, tiredness or jaundice. His complete blood count, renal function and liver enzyme levels were normal, as were the results of ultrasonography of the abdomen. An upper gastrointestinal endoscopic scan showed a diverticulum in the fundus of the stomach (Figure 1). The pain was reproduced by probing the diverticulum with biopsy forceps as well as by insufflating it with air. The patient's symptoms improved after four weeks' therapy with proton pump inhibitors.

\section{Discussion}

Gastric diverticula are uncommon, the rates of detection by endoscopy ranging from $0.01 \%-0.11 \%$. $^{1}$ They usually occur in middle-aged people, with equal distribution among men and women, and can be congenital or acquired. ${ }^{1,2}$ Areas of weakness caused by splitting of the longitudinal muscle fibres, an absence of peritoneal membrane and perforating arterioles may predispose to the formation of a diverticulum.

Gastric diverticula are often single, varying in size from 1 to $3 \mathrm{~cm}$. However, multiple and larger diverticula have also been noted, usually adjacent to the gastroesophageal junction and along the lesser curvature or posterior gastric wall. ${ }^{2}$ Gastric cardia diverticula may simulate a left adrenal mass; those on the posterior wall could herniate through the dorsal mesentery and fuse with the left posterior body wall. ${ }^{3}$

Patients with gastric diverticula are often asymptomatic, although they may present with dyspepsia, vomiting and abdominal pain. Complications such as ulceration, perforation, hemorrhage, torsion and malignancy are uncommon. ${ }^{2,4}$ The condition is diagnosed incidentally by radiologic or endoscopic examination. There is no specific treatment required for an asymptomatic diverticulum. ${ }^{2}$

From the Department of Gastroenterology, Stanley Medical College, Chennai, India

CMAJ 2010. DOI:10.1503/cmaj.090832

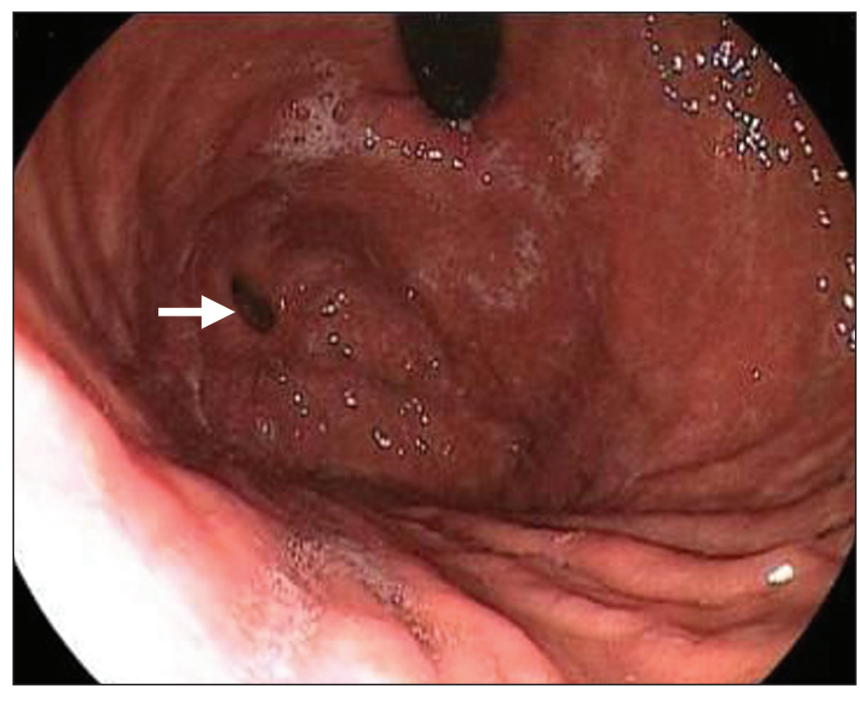

Figure 1: Upper gastrointestinal endoscopic scan showing a diverticulum (arrow) in the fundus of the stomach.

Surgical resection is recommended when the diverticulum is large, symptomatic or complicated by bleeding, perforation or malignancy. Both open and laparoscopic resection yield good results. Perioperative gastroscopy can help locate the diverticulum in difficult situations. Laparoscopic access to the posterior aspect of the gastric fundus is possible after the gastrocolic ligament has been divided. ${ }^{1}$

Competing interests: None declared.

\section{REFERENCES}

1. Donkervoort SC, Baak LC, Blaauwgeers JL, et al. Laparoscopic resection of a symptomatic gastric diverticulum: a minimally invasive solution. JSLS 2006;10:525-7.

2. Harford W, Jeyarajah R. Diverticula of the pharynx, esophagus, stomach, and small intestine. In: Feldman M, Friedman L, Brandt L, et al. editors. Sleisenger \& Fordtran's gastrointestinal and liver disease. 8th ed. Philadelphia (PA): Saunders; 2006. p. 465-77.

3. Schwartz AN, Goiney RC, Graney DO, Gastric diverticulum simulating an adrenal mass: CT appearance and embryogenesis. AJR Am J Roentgenol 1986;146:553-4.

4. Gibbons CP, Harvey L. An ulcerated gastric diverticulum — a rare cause of haematemesis and melaena. Postgrad Med J 1984;60:693-5. 